\section{CARDIOVASCULAR INNERVATION}

By G. A. G. Mitchell, O.B.E., T.D., M.B., Ch.M., D.Sc. Pp. xii +356 , with 217 illustrations, many in colour. Edinburgh: E. \& S. Livingstone Ltd. 1956. $55 \mathrm{~s}$.

One's first impression of this book is that it covers a much wider field than the title suggests. The first six of the ten chapters, accounting for nearly a half of the text, are taken up with a general account of the autonomic nervous system, the question of autonomic representation in the cerebrum and other parts of the central nervous system and general discussion of the nature of the pre- and postganglionic autonomic outflow, and of the sensory innervation of viscera. An excellent account is given of controversial questions concerning the relationship between postganglionic nerve fibres and the effector organs, smooth muscle or secreting cells. A very convincing case is made for the nervous character of the terminal reticulum and the 'interstitial cells of Cajal', both of which are well illustrated in numerous microphotographs, and their possible role as intermediaries between the postganglionic fibre and the effector cell is discussed. The importance of this subject in relation to such fundamental matters as the neurone theory of nervous organization and the chemical transmission of nervous stimuli is obvious, and though not everyone will agree with the author's views, the discussion, fully documented, is a valuable addition to neurological literature.

The discussion of afferent fibres and their endings is perhaps somewhat less satisfactory, and it is not clear how far the terminal nervous network described and illustrated in such regions as the depressor area of the aorta differ, if at all, from the terminal nerve networks which are thought to be related to efferent fibres. Possibly a similar network could serve both afferent and efferent functions, but it is clear that much more work is needed in this field before firm conclusions can be reached. As a relatively minor point, one may also ask whether the use of the term ' autonomic' for afferent fibres serves any useful purpose apart from demonstrating the 'irrationality' of those who differ from the author in the use of terminology. It seems possible that such terms as autonomic and somatic, as applied to afferent nerves, have outlined their usefulness; the categories they represent cannot be defined precisely, and they seem to offer no advantages over a classification in terms of the structures supplied, e.g. visceral, cutaneous, etc.
The second half of the book is taken up with detailed account of vascular innervation, both efferent and afferent, in the different regions of the body. The account is exhaustive both from the macroscopic and microscopic points of view and functional considerations are kept in mind, thougho the primary purpose is always to describe structure $\frac{O}{3}$ Since so much is based on dissections and prepara tions made by the author, or of which the author has direct experience, the book has an authority whick is lacking in many text-books, and an individuat character which makes for pleasant reading. As an account of what is known of the structural basis of cardiovascular innervation throughout the human body, there is no doubt that the book provides aD most valuable basis both for surgery and for further research, whether anatomical or physiological. A full bibliography is provided.

\section{CHILD HEALTH AND DEVELOPMENT}

Edited by R. W. B. Ellis, O.B.E., M.A., M.E F.R.C.P., F.R.S.E. Second Edition. Pp. $x$

525. London: J. \& A. Churchill Ltd. I 956 $42 \mathrm{~s}$.

It will be a considerable advance if it becomes impossible for a candidate to be successful at an? examination for a Diploma in Child Health unless he knows all that is recorded in this book. The best chapter is one of the shortest-“" The Establishment of Feeding Habits": all doctors and nurseso who deal with children should remember that it is. not their duty to make children " adapt themselves to feeding régimes which reckon neither with the urgency and variability of infantile instinctive 0 needs nor with the compelling power of pleasurable experiences." This is a good book.

T.S.

\section{HANDBOOK OF PEDIATRICS}

By Henry K. Silver, M.D., C. Henry Kempe, N M.D. and Henry B. BruYN, M.D. Pp. 548 N California: Lange Medical Publications. I $955 . \frac{\mathrm{O}}{\mathrm{O}}$ $\$ 3.00$.

Your reviewer must frankly admit that this handbook is not the ideal answer to the student's wish for a small volume about the diseases of children. The main reason is that he will not learn $\frac{0}{0}$ from it which of the many symptoms or signs of disease are the really important ones. 